\title{
Correlation of protein structure and dynamics
}

\section{to scalar couplings across hydrogen bonds}

\author{
Hans-Jürgen Sass, ${ }^{1, *}$ Franziska Fang-Fang Schmid, ${ }^{2}$ and Stephan Grzesiek ${ }^{l, *}$ \\ ${ }^{1}$ Biozentrum and ${ }^{2}$ Department Chemie, University of Basel, Klingelbergstrasse 50,
}

4056 Basel, Switzerland

\section{Supporting Information}

M. J. Frisch; G. W. Trucks; H. B. Schlegel; G. E. Scuseria; M. A. Robb; J. R.

Cheeseman; J. A. Montgomery Jr.; T. Vreven; K. N. Kudin; J. C. Burant; J. M.

Millam; S. S. Iyengar; J. Tomasi; V. Barone; B. Mennucci; M. Cossi; G. Scalmani; N. Rega; G. A. Petersson; H. Nakatsuji; M. Hada; M. Ehara; K. Toyota; R. Fukuda; J. Hasegawa; M. Ishida; T. Nakajima; Y. Honda; O. Kitao; H. Nakai; M. Klene; X. Li; J. E. Knox; H. P. Hratchian; J. B. Cross; C. Adamo; J. Jaramillo; R. Gomperts; R. E. Stratmann; O. Yazyev; A. J. Austin; R. Cammi; C. Pomelli; J. W. Ochterski; P. Y. Ayala; K. Morokuma; G. A. Voth; P. Salvador; J. J. Dannenberg; V. G. Zakrzewski; S. Dapprich; A. D. Daniels; M. C. Strain; O. Farkas; D. K. Malick; A. D. Rabuck; K. Raghavachari; J. B. Foresman; J. V. Ortiz; Q. Cui; A. G. Baboul; S. Clifford; J. Cioslowski; B. B. Stefanov; G. Liu; A. Liashenko; P. Piskorz; I. Komaromi; R. L. Martin; D. J. Fox; T. Keith; M. A. Al-Laham; C. Y. Peng; A. Nanayakkara; M. Challacombe; P. M. W. Gill; B. Johnson; W. Chen; M. W. Wong; C. Gonzalez; Pople, J. A. Gaussian 03, Revision B.03; Gaussian Inc: Pittsburgh PA, 2003.

Case, D. A.; Pearlman, D. A.; Caldwell, J. W.; III, T. E. C.; Wang, J.; Ross, W. S.; Simmerling, C. L.; Darden, T. A.; Merz, K. M.; Stanton, R. V.; Cheng, A. L.; Vincent, J. J.; Crowley, M.; Tsui, V.; Gohlke, H.; Radmer, R. J.; Duan, Y.; Pitera, J.; Massova, I.; Seibel, G. L.; Singh, U. C.; Weiner, P. K.; Kollman, P. A. AMBER 7; University of California: San Francisco, 2002. 